\title{
Molecular Cytogenetics (FISH, GISH) of Coccinia grandis: A ca. 3 myr-Old Species of Cucurbitaceae with the Largest Y/Autosome Divergence in Flowering Plants
}

\author{
A. Sousa ${ }^{\text {a }}$ J. Fuchs ${ }^{\text {b S.S. Renner }}{ }^{\text {a }}$ \\ a Systematic Botany and Mycology, University of Munich (LMU), Munich, and ${ }^{\mathrm{b}}$ Cytogenetics and Genome Analysis, \\ Leibniz Institute of Plant Genetics and Crop Plant Research (IPK), Gatersleben, Germany
}

\section{Key Words}

$5 \mathrm{~S}$ and $45 \mathrm{~S} \mathrm{rDNA} \cdot \mathrm{C}$-Banding $\cdot \mathrm{FISH} \cdot \mathrm{GISH} \cdot \mathrm{Sex}$

chromosome $\cdot$ Telomeres

\begin{abstract}
The independent evolution of heteromorphic sex chromosomes in 19 species from 4 families of flowering plants permits studying $X / Y$ divergence after the initial recombination suppression. Here, we document autosome/Y divergence in the tropical Cucurbitaceae Coccinia grandis, which is ca. 3 myr old. Karyotyping and C-value measurements show that the $C$. grandis $Y$ chromosome has twice the size of any of the other chromosomes, with a male/female C-value difference of $0.094 \mathrm{pg}$ or $10 \%$ of the total genome. FISH staining revealed $5 \mathrm{~S}$ and $45 \mathrm{~S}$ rDNA sites on autosomes but not on the $Y$ chromosome, making it unlikely that rDNA contributed to the elongation of the $\mathrm{Y}$ chromosome; recent end-to-end fusion also seems unlikely given the lack of interstitial telomeric signals. GISH with different concentrations of female blocking DNA detected a possible pseudo-autosomal region on the $\mathrm{Y}$ chromosome, and C-banding suggests that the entire $Y$ chromosome in C. grandis is heterochromatic. During meiosis, there is an end-to-end connection between the $\mathrm{X}$ and the $Y$ chromosome, but the $X$ does not otherwise differ from the remaining chromosomes. These findings and a re-
\end{abstract}

view of plants with heteromorphic sex chromosomes reveal no relationship between species age and degree of sex chromosome dimorphism. Its relatively small genome size $(0.943$ $\mathrm{pg} / 2 \mathrm{C}$ in males), large $\mathrm{Y}$ chromosome, and phylogenetic proximity to the fully sequenced Cucumis sativus make $C$. grandis a promising model to study sex chromosome evolution.

Copyright $\odot 2012$ S. Karger AG, Basel

Sex chromosomes in land plants are known from 48 species in 20 families of liverworts, gymnosperms, and flowering plants, where they evolved independently and over widely different time spans [Ming et al., 2011]. Indeed, the sex chromosomes of liverworts differ so fundamentally from those of vascular plants in functioning during the haploid phase of the life cycle, that they might better be considered a third chromosomal sex-determining system, besides X/Y and W/Z systems [Bachtrog et al., 2011]. These independent origins offer the opportunity to compare incipient sex chromosomes, such as those of $\mathrm{Pa}$ paya and Fragaria, which are just 0.5-2.2 myr old [Liu et al., 2004; Spigler et al., 2008, 2010; Yu et al., 2008], with older ones, such as those of Silene or Rumex, which are thought to be over 10 myr old [Moore et al., 2003; Navajas-Pérez et al., 2005; but see Discussion section]. So far,

\section{KARGER}

Fax +4161306 1234

E-Mail karger@karger.ch

www.karger.com
(C) 2012 S. Karger AG, Basel

$1424-8581 / 13 / 1392-0107 \$ 38.00 / 0$

Accessible online at:

www.karger.com/cgr
Susanne S. Renner

Systematic Botany and Mycology

University of Munich (LMU)

Menzinger Strasse 67, DE-80638 Munich (Germany)

E-Mail renner@lrz.uni-muenchen.de 
heteromorphic sex chromosomes are reliably known from 19 species of Cannabaceae, Caryophyllaceae, $\mathrm{Cu}$ curbitaceae, and Polygonaceae [Ming et al., 2011]. About half of the 19 species have been studied with moleculargenetic tools (e.g. Sakamoto et al. [2000]: Cannabis (Cannabaceae); Karlov et al. [2003], Divashuk et al. [2011], Grabowska-Joachimiak et al. [2011]: Humulus (Cannabaceae); Ruiz Rejón et al. [1994], Shibata et al. [1999, 2000], Mariotti et al. [2006, 2009], Cuñado et al. [2007]: Rumex (Polygonaceae); Uchida et al. [2002], Lengerova et al. [2004], Hobza et al. [2006], Cermak et al. [2008], Kejnovsky et al. [2009]: Silene (Caryophyllaceae)).

Conspicuously neglected among the plants with heteromorphic sex chromosomes is the Cucurbitaceae Coccinia grandis. Classic cytogenetic work established that the $\mathrm{Y}$ chromosome in this species is much larger than the other chromosomes [Kumar and Deodikar, 1940; Bhaduri and Bose, 1947; Chakravorti, 1948; Kumar and Vishveshwaraiah, 1952], and experimental work in the 1970s confirmed the sex-determining role of the single Y chromosome [Roy and Roy, 1971]. In spite of the growing interest in plant sex chromosomes [Ming et al., 2011], modern cytogenetic methods have not been applied to $C$. grandis nor has the size of its genome been determined. C. grandis belongs to a small genus (25 species) that is phylogenetically close to Cucumis, the genus containing cucumber and melon [Schaefer and Renner, 2011]. A dated molecular phylogeny for 24 Coccinia species including C. grandis is available [Holstein and Renner, 2011].

Here, we characterize the karyotype of male and female C. grandis using mitotic and meiotic cell preparations, flow cytometry, FISH with telomere and $5 \mathrm{~S}$ and $45 \mathrm{~S}$ rDNA probes, and GISH to evaluate differences between the sexes. We also review XY chromosome size differences in land plants (including the haploid-dominant bryophytes), relating the differences to species ages inferred from molecular-clock studies. The questions we wanted to answer were (i) if rDNA or end-to-end fusions likely have contributed to the elongation of the Y chromosome in C. grandis and (ii) if there is a relationship between the age of vascular plant sex chromosomes and the extent of $\mathrm{X} / \mathrm{Y}$ or $\mathrm{Y} / \mathrm{autosome}$ morphological divergence.

\section{Materials and Methods}

\section{Plant Material}

C. grandis (L.) Voigt (including the illegitimate name C. indica Wight \& Arn.) ranges from tropical Africa to subtropical and tropical Asia and is an invasive weed on Hawaii, other Pacific is- lands, and in tropical Australia. It belongs to Coccinia, a genus of 25 species in sub-Saharan Africa, all of them dioecious climbers. A recent revision of the genus has clarified the boundaries among the species [Holstein, 2012], and a dated molecular phylogeny that includes all but one of the species indicates that the entire genus evolved over just 7 myr [Holstein and Renner, 2011].

Seeds for this study were collected in spring 2011 on the campus of Kakatiya University in Vidyaranyapura, located in the northern part of Bangalore, state of Warangal, India. In Munich, they were germinated on moist filter paper and then transferred to plastic pots with standard potting soil. Female and male plants were identified by chromosome preparations, and later verified by checking if their flowers were male or female. Plants are still in cultivation in the greenhouses of the Botanical Garden Munich, and a voucher has been deposited in the herbarium of Munich (Sousa and Silber 1 and 2).

\section{Flow Cytometric Genome Size Measurement}

Nuclei were isolated from young leaves of 1 male and 1 female C. grandis, the sex of which was known since the plants had flowered. Measurements were made on 2 leaves per sex, with each measurement repeated 6 times on 2 different days. Roughly 50 $\mathrm{mm}^{2}$ of leaf tissue were co-chopped with equal amounts of young leaf tissue of Glycine max, cv. Cina 5202 'Voran' (IPK gene bank accession number SOJA 392; 2 C $=2.23$ pg; Borchert et al. [2007]) as an internal reference standard using a razor blade in a Petri dish containing $0.7 \mathrm{ml}$ of nuclei isolation buffer [Galbraith et al., 1983] supplemented with $1 \%$ polyvinylpyrrolidone $25,0.1 \%$ Tween $20^{\circledR}$, DNase-free RNase $(50 \mu \mathrm{g} / \mathrm{ml})$ and propidium iodide $(50 \mu \mathrm{g} / \mathrm{ml})$. The nuclei suspension was filtered through a $35-\mu \mathrm{m}$-mesh cell strainer cap into a $5-\mathrm{ml}$ polystyrene falcon tube. After at least 15 min of incubation, DNA content measurement was performed on the FACStar ${ }^{\text {PLUS }}$ cell sorter (BD Biosciences) equipped with an argon ion laser INNOVA 90C (Coherent). Approximately 10,000 particles per sample were analyzed, and fluorescence intensities of nuclei were measured using the software CELL Quest ver. 3.3 (BD Biosciences). The absolute DNA amounts were calculated based on the values of the G1 peak means.

\section{Chromosome Preparation}

Mitotic metaphase chromosomes were prepared from root tips pre-treated in $2 \mathrm{mM} 8$-hydroxyquinoline for $20 \mathrm{~h}$ at $4{ }^{\circ} \mathrm{C}$, fixed in freshly prepared 3:1 (v/v) ethanol/glacial acetic acid at room temperature overnight and kept at $-20^{\circ} \mathrm{C}$. Fixed root tips were washed 3 times for $5 \mathrm{~min}$ in distilled water, digested with $1 \%$ cellulase (w/v; Onozuka RS, Serva), $0.4 \%$ pectolyase (w/v; Sig$\mathrm{ma}), 0.4 \%$ cytohelicase (w/v; Sigma) in citric buffer, $\mathrm{pH} 4.8$ for 30 min at $37^{\circ} \mathrm{C}$, dissected in a drop of $45 \%$ acetic acid and squashed. Coverslips were removed after freezing in dry ice and preparations were air-dried at room temperature. The quality of spreads was checked microscopically using phase-contrast, and only preparations with at least 10 well-spread metaphases were used for FISH/GISH.

Meiotic preparations were made from anthers of young buds. Anthers were fixed in 3:1 (v/v) ethanol/glacial acetic acid at room temperature overnight and stored at $-20^{\circ} \mathrm{C}$. Fixed anthers were quickly washed in distilled water, dissected in a drop of $45 \%$ acetic acid and squashed. Coverslips were removed after freezing, air-dried at room temperature, and the best slides were stained with DAPI $(2 \mu \mathrm{g} / \mathrm{ml})$. After taking pictures, slides were destained 
in 3:1 (v/v) ethanol/glacial acetic acid at room temperature for 30 min, kept overnight at $10^{\circ} \mathrm{C}$ in $100 \%$ ethanol, air-dried and kept at room temperature until they were used for C-banding.

\section{DNA Probes}

The heterologous ribosomal DNA sequences used as FISH probes were the 18S-5.8S-25S rDNA repeat unit of Arabidopsis thaliana in the pBSK+ plasmid, labeled with digoxigenin-11dUTP (Roche) by nick translation, and a 349-bp fragment of the 5S rRNA gene repeated unit from Beta vulgaris cloned into pBSK+ [Schmidt et al., 1994], labeled with biotin-16-dUTP (Roche) by PCR. An Arabidopsis-like telomeric probe was amplified by PCR according to Ijdo et al. [1991] using the oligomer primers $\left(5^{\prime}\right.$ TTTAGGG- $\left.3^{\prime}\right)_{5}$ and $\left(5^{\prime} \text {-CCCTAAA- } 3^{\prime}\right)_{5}$ and labeled with digoxigenin-11-dUTP by nick translation.

For GISH, genomic DNA from C. grandis male and female plants was isolated using the DNeasy Plant Maxi Kit (QIAGEN). Genomic DNA $(1 \mu \mathrm{g})$ was autoclaved for 2 min to a fragment size range of 200-400 bp and labeled with digoxigenin-11-dUTP or biotin-16-dUTP (Roche) by nick translation. Blocking DNA was obtained by autoclaving total genomic DNA for $5 \mathrm{~min}$, yielding fragments of approximately 100-200 bp. In GISH experiments, the probe/block ratio was 1:47, 1:70 and 1:100. Digoxigenin-labeled probes were detected with anti-digoxigenin conjugated with FITC (Roche) and biotin-labeled probes with ExtrAvidin conjugated with Cy3 (Sigma).

\section{FISH}

FISH was carried out using the method of Schwarzacher and Heslop-Harrison [2000] with minor modifications. Slides were pre-treated with $100 \mu \mathrm{g} / \mathrm{ml}$ of RNase A in $2 \times$ SSC buffer for $1 \mathrm{~h}$ at $37^{\circ} \mathrm{C}$ and washed 3 times for $5 \mathrm{~min}$ in $2 \times$ SSC. They were then treated with $10 \mu \mathrm{g} / \mathrm{ml}$ Pepsin (Sigma) in $0.01 \mathrm{~N} \mathrm{HCl}$ for $20 \mathrm{~min}$ at $37^{\circ} \mathrm{C}$, washed twice for $5 \mathrm{~min}$ in $2 \times$ SSC, post-fixed in $4 \%$ formaldehyde solution (Roth) for $5 \mathrm{~min}$ at room temperature, washed again 3 times for $5 \mathrm{~min}$ in $2 \times \mathrm{SSC}$, dehydrated for $5 \mathrm{~min}$ in a 70 and $100 \%$ ethanol series and air-dried for at least $1 \mathrm{~h}$ at room temperature. Hybridization mixtures consisted of $50 \%$ formamide $(\mathrm{w} / \mathrm{v}), 2 \times$ SSC, $10 \%$ dextran sulfate $(\mathrm{w} / \mathrm{v})$ and $70-200 \mathrm{ng}$ of labeled probe. The hybridization mix was denatured at $75^{\circ} \mathrm{C}$ for $10 \mathrm{~min}$ and immediately cooled on ice for $10 \mathrm{~min} ; 10-15 \mu l$ of the mix was then added to each slide and covered with a glass coverslip. For hybridization, the chromosomes, together with the hybridization mixture, were denatured for $5 \mathrm{~min}$ at $75^{\circ} \mathrm{C}$. Hybridization was carried out in a humid chamber at $37^{\circ} \mathrm{C}$ for $20 \mathrm{~h}$. After hybridization, the slides were washed 3 times for $5 \mathrm{~min}$ in $2 \times \mathrm{SSC}$ at $42^{\circ} \mathrm{C}$, $5 \mathrm{~min}$ in $2 \times \mathrm{SSC}$ at room temperature and $5 \mathrm{~min}$ in $2 \times \mathrm{SSC} / 0.1 \%$ $(\mathrm{v} / \mathrm{v})$ Tween 20 at room temperature. For digoxigenin and biotin detection, slides were incubated in blocking buffer $(2 \%$ BSA in $2 \times$ SSC) in a humid chamber for $30 \mathrm{~min}$ at $37^{\circ} \mathrm{C}$, followed by incubation with anti-DIG-FITC conjugate (Roche) and streptavidin-Cy3 conjugate (Sigma) at $37^{\circ} \mathrm{C}$ for $1 \mathrm{~h}$. Excess of antibody was removed by washing the slides twice for $7 \mathrm{~min}$ in $2 \times$ SSC and for $7 \mathrm{~min}$ in $2 \times \mathrm{SSC} / 0.1 \%(\mathrm{v} / \mathrm{v})$ Tween 20 at $42^{\circ} \mathrm{C}$. The chromosomes were counterstained with DAPI $(2 \mu \mathrm{g} / \mathrm{ml})$ and mounted in Vectashield (Vector).

\section{GISH}

The GISH procedure resembled the FISH procedure except that blocking DNA was added to the hybridization mixture. The latter thus consisted of $50 \%$ formamide (w/v), $2 \times$ SSC, $10 \%$ dextran sulfate $(\mathrm{w} / \mathrm{v}), 83 \mathrm{ng}$ of digoxigenin-labeled C. grandis male DNA probe, and 3,500-8,500 ng of non-labeled genomic DNA of a C. grandis female. To achieve a 1:47, 1:70 or 1:100 ratio between probe and blocking DNA we used C. grandis female DNA at concentrations of $3,928,6,017$ and $8,300 \mathrm{ng}$.

\section{C-Banding}

C-banding was performed according to Schwarzacher et al. [1980] with minor modifications. Slides were left for $3 \mathrm{~d}$ at room temperature and then incubated in $45 \%$ acetic acid at $60^{\circ} \mathrm{C}$ for 10 min, washed for 1 min in running tap water, dried using an air pump, and incubated in barium hydroxide (Roth) at room temperature for $10 \mathrm{~min}$. The crystals of barium hydroxide were removed by briefly washing the slides in running tap water, followed by a rinse in $45 \%$ acetic acid, another 2 min in running tap water and a final rinse in distilled water. The slides were dried using an air pump, and incubated in $2 \times \mathrm{SSC}$ at $60^{\circ} \mathrm{C}$ for $1 \mathrm{~h} 20 \mathrm{~min}$. After the incubation, the slides were washed in distilled water, dried, counterstained with DAPI $(2 \mu \mathrm{g} / \mathrm{ml})$, and mounted in Vectashield (Vector).

\section{Image Analysis}

Images were taken with a Leica DMR microscope equipped with a KAPPA-CCD camera and the KAPPA software. They were optimized for best contrast and brightness using Adobe Photoshop CS3 version 10.0 .

\section{Karyotype Analysis}

Chromosomes and positions of rDNA sites were measured using Adobe Photoshop CS3, and idiograms were constructed based on the analysis of 4 well-spread metaphases, with chromosomes ordered from the largest to the shortest pair, except for the Y chromosome. The $\mathrm{X}$ chromosome was assumed to be the smallest chromosome not pairing with an equal-sized autosome; no specific $\mathrm{X}$ probes are so far known for $C$. grandis. The chromosome arm ratio (AR, defined as length of the long arm/length of the short arm) was used to classify chromosomes as metacentric $(\mathrm{AR}=1-1.4)$, submetacentric $(\mathrm{AR}=1.5-2.9)$, or acrocentric $(\mathrm{AR} \geq 3.0)$ following Guerra [1986].

Review of X/Y or Y/Autosome Size Differences in Land Plants

Vascular plants with heteromorphic sex chromosomes were tabulated based on Ming et al. [2011] and the most recent available data on their karyotypes, chromosome lengths, and male/female $\mathrm{C}$-value differences were compiled from the literature. Divergence times for the relevant species inferred with molecular clocks were compiled from phylogenetic studies.

\section{Results}

\section{Karyotype, Idiogram, Meiosis and FISH Results}

C. grandis females have a karyotype of $2 \mathrm{n}=22+\mathrm{XX}$ and males have $2 \mathrm{n}=22+\mathrm{XY}$. As the unpaired large chromosome correlates with maleness in the phenotype, $C$. grandis has heteromorphic sex chromosomes. On an agarose gel (online suppl. fig. 1, for all online suppl. materi- 


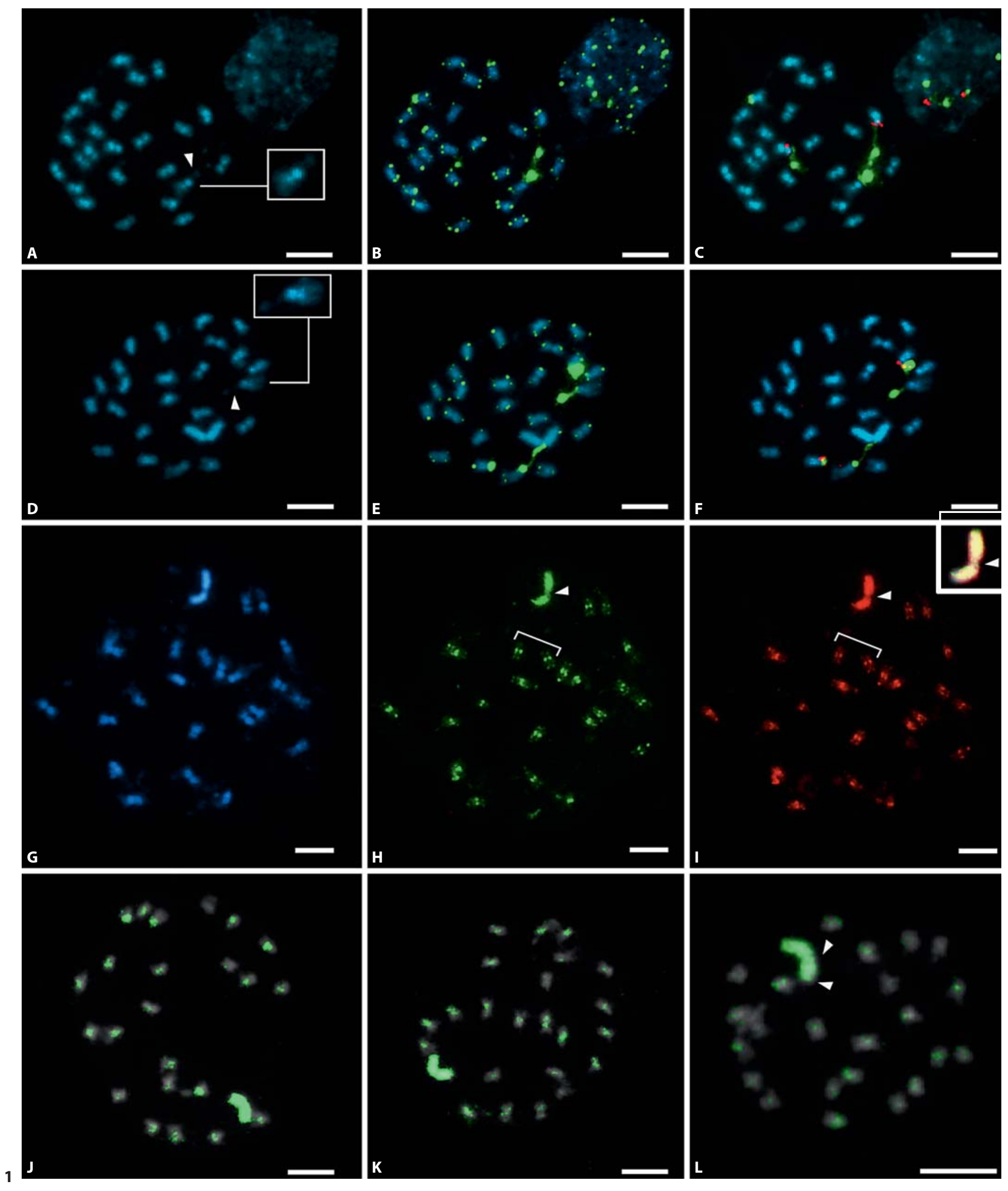


Fig. 2. Idiograms of the haploid chromosome complement of C. grandis, including 5S (red) and 45S (green) rDNA sites (although only shown in the male, they are equally distributed in the female). Chromosome pairs were put together by similarity. The $\mathrm{X}$ chromosome is shown beside the Y chromosome in the male. Telomere sites were detected in all chromosome ends and are not represented in this idiogram. Bar corresponds to $5 \mu \mathrm{m}$.

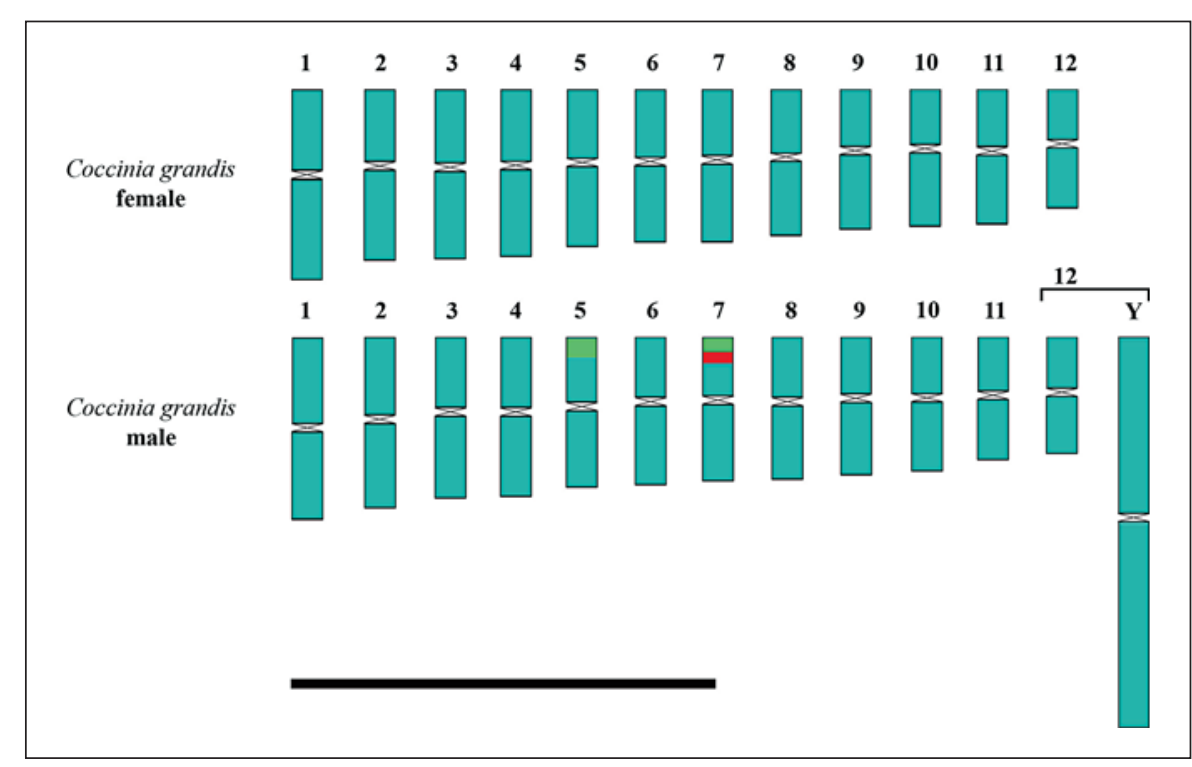

als, see www.karger.com/doi/10.1159/000345370), autoclaved C. grandis female DNA was more stable than male DNA.

Two 45S rDNA sites and one 5S rDNA site were detected in both male and female individuals. The two $45 \mathrm{~S}$ rDNA sites were always located at the terminal regions of the chromosomes, and the $5 \mathrm{~S}$ rDNA site was adjacent to one $45 \mathrm{~S}$ rDNA site (fig. 1C, F). Secondary constrictions were observed in at least 1 chromosome per karyotype in both sexes (see arrowheads in fig. 1A, D and their insets). The Arabidopsis-like telomeric probe revealed telomere sequences at the ends of all chromosomes in both females and males (fig. 1B, E), but no interstitial telomere sites.

Fig. 1. FISH (A-F) and GISH (G-L) on mitotic metaphase chromosomes of C. grandis. A, D DAPI stained chromosomes $(2 \mathrm{n}=24)$ with 24 homomorphic chromosomes in a female plant, and 23 homomorphic chromosomes and a large heteromorphic Y chromosome in a male plant, respectively. Insets show magnified chromosomes with arrowheads marking satellites. B, E Distribution of telomeric sequences (small green dots located at the end of the chromosomes) and 45S rDNA (4 strong green signals). CF Bicolor FISH with $45 \mathrm{~S}$ rDNA (green) and $5 \mathrm{~S}$ rDNA probe (red). DAPI male metaphase (G), and GISH using male genomic probe (H) and female genomic probe (I). Arrowheads in $\mathbf{H}$ and $\mathbf{I}$ show the Y centromere region; the Inset (I) shows an enlarged Y chromosome with its centromeric region not strongly labeled by either genomic probe. J-L GISH using $47 \times, 70 \times$, and $100 \times$ excess of female blocking DNA, respectively. Arrowheads in $\mathbf{L}$ show small hybridization gaps. Scale bars correspond to $5 \mu \mathrm{m}$.

Molecular Cytogenetics (FISH, GISH) of Coccinia grandis
Figure 2 shows idiograms of C. grandis male and female individuals. rDNA sites are presented in figure 2 only in males; females had the same numbers and positions of rDNA.

In meiosis, 12 bivalents could be seen in late prophase I (diakinesis) and in the metaphase plate (fig. 3). Clear end-to-end connections between the $\mathrm{X}$ and the $\mathrm{Y}$ chromosome were observed (fig. 3A, C, E; as also reported by Bhaduri and Bose [1947]).

\section{GISH and C-Banding Results}

GISH experiments were performed with males, using male and female genomic probes. Figure $1 \mathrm{H}$ shows that the male genomic probe labeled the (peri-)centromeric and some subterminal regions plus the complete $\mathrm{Y}$ chromosome. When the same metaphase preparation was hybridized with the female genomic probe (fig. 1I), the centromeric regions and the $\mathrm{Y}$ chromosome again were intensely labeled. The overlap of male and female probes (fig. 1I, inset using DAPI in gray) on the $\mathrm{Y}$ chromosome shows that the centromeric region was not well-labeled in comparison to the other chromosomes (arrowheads fig. $1 \mathrm{H}, \mathrm{I})$, suggesting that the centromere sequences of the autosomes/X chromosome and the $\mathrm{Y}$ chromosome differ in DNA composition. In a few chromosomes, including the $\mathrm{Y}$ chromosome, the subterminal regions were predominantly labeled with male genomic probe (these chromosomes are marked by brackets in fig. $1 \mathrm{H}, \mathrm{I}$ ), indicating that subterminal repetitive sequences may have accumulated on the Y chromosome.

Cytogenet Genome Res 2013;139:107-118 

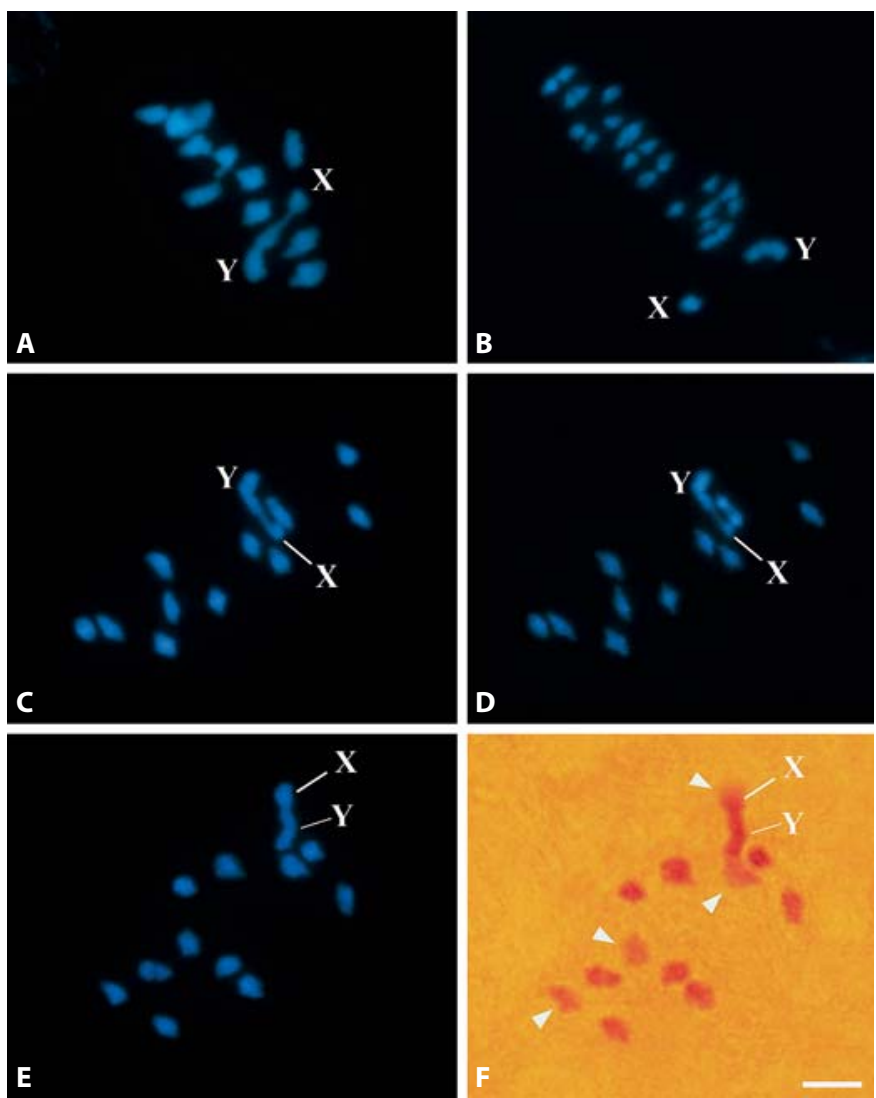

Fig. 3. Meiosis I in a C. grandis male, with the position of the sex chromosomes $(\mathrm{X} / \mathrm{Y})$ indicated in all cells. A Twelve bivalents in metaphase I moving together along the metaphase plate. B Early anaphase I with the migration of bivalents and X/Y chromosomes to opposite poles of the cell. C, E Cells stained with DAPI before C-banding (D, F). D Bivalents stained with DAPI showing no detectable morphological distinction between the $\mathrm{X}$ and autosomes. F Cell stained with Giemsa showing weakly stained bivalents (arrowheads) including the terminal region of X chromosome. Bar corresponds to $5 \mu \mathrm{m}$.

When male genomic probes were used with female blocking DNA in different concentrations, the intensity of the hybridization signals in the centromeric region of the chromosomes decreased or disappeared entirely with increasing concentration of female DNA. With $47 \times$ excess of blocking DNA, the Y chromosome was well-labeled as were most of the chromosomes (fig. 1J); with $70 \times$ excess of blocking DNA, the Y chromosome still was well-labeled, but a few chromosomes exhibited no or weak hybridization signals (fig. $1 \mathrm{~K}$ ); with $100 \times$ excess of blocking DNA, the Y chromosome started to present hybridization gaps not labeled by the male genomic probe, and 1 terminal region did not show any detectable hy- bridization signal (fig. 1L, arrowheads). The reduction of the signal strength presumably is associated with similar repetitive sequences shared by male and female C. grandis.

C-banded heterochromatic regions in females were mostly concentrated in centromeric/pericentromeric regions (fig. 4B, C) while in males (fig. $4 \mathrm{E}, \mathrm{F}$ ) they were diffusely pericentromeric/subterminal. The Y chromosome showed the same DAPI intensity before and after $\mathrm{C}$-banding, again suggesting that the $\mathrm{Y}$ chromosome in C. grandis is heterochromatic. Using Giemsa staining (fig. 4C, F), female pre-metaphase chromosomes were all more or less well-stained while male pre-metaphases showed only few chromosomes, including the Y chromosome, with strong Giemsa-labeling.

In meiotic cells stained with DAPI, bivalents in metaphase I displayed few differences before and after Cbanding (see fig. $3 \mathrm{C}, \mathrm{D}$ ). The terminal region of the $\mathrm{X}$ chromosome, but not the Y chromosome, was DAPI-positive, implying that the pseudoautosomal region is mainly euchromatic (fig. 3D). The autosomes were more intensely stained in the internal region of each bivalent, and no detectable morphological distinction could be observed between the $\mathrm{X}$ and the autosomes (fig. 3D). With Giemsa-staining (fig. 3F), some bivalents in late prophase I exhibited less labeling than others (see arrowheads) after C-banding, and the free terminal region of the X chromosome was less strongly labeled than its other end, connected to the $\mathrm{Y}$ chromosome.

\section{Chromosome Measurements, C-Values and}

Comparison with Other Vascular Plant Sex

\section{Chromosomes}

Chromosome lengths in the female varied from 1.35 to $2.26 \mu \mathrm{m}$ and in the male from 1.33 to $4.71 \mu \mathrm{m}$. The largest autosome in males was $2.28 \mu \mathrm{m}$ long, meaning that the $\mathrm{Y}$ chromosome, with $4.71 \mu \mathrm{m}$, is around twice as long as the largest chromosome. On the basis of their centromere position, all C. grandis chromosomes have an AR index of 1-1.4, making them metacentric (see table 1). Based on measurements on nuclei isolated from young leaf tissue, female individuals have a C-value of 0.849 $\mathrm{pg} / 2 \mathrm{C}$ and male individuals of $0.943 \mathrm{pg} / 2 \mathrm{C}$ (table 2).

Table 3 summarizes data on $\mathrm{X}$ and $\mathrm{Y}$ chromosome lengths, $\mathrm{C}$-values, and inferred ages for vascular plant species with heteromorphic sex chromosomes. Species with sex chromosomes are usually characterized by ARs (p/q) and relative, not absolute lengths because length to some extent depends on the preparation protocol and environmental factors. The data available so far reveal no relation- 

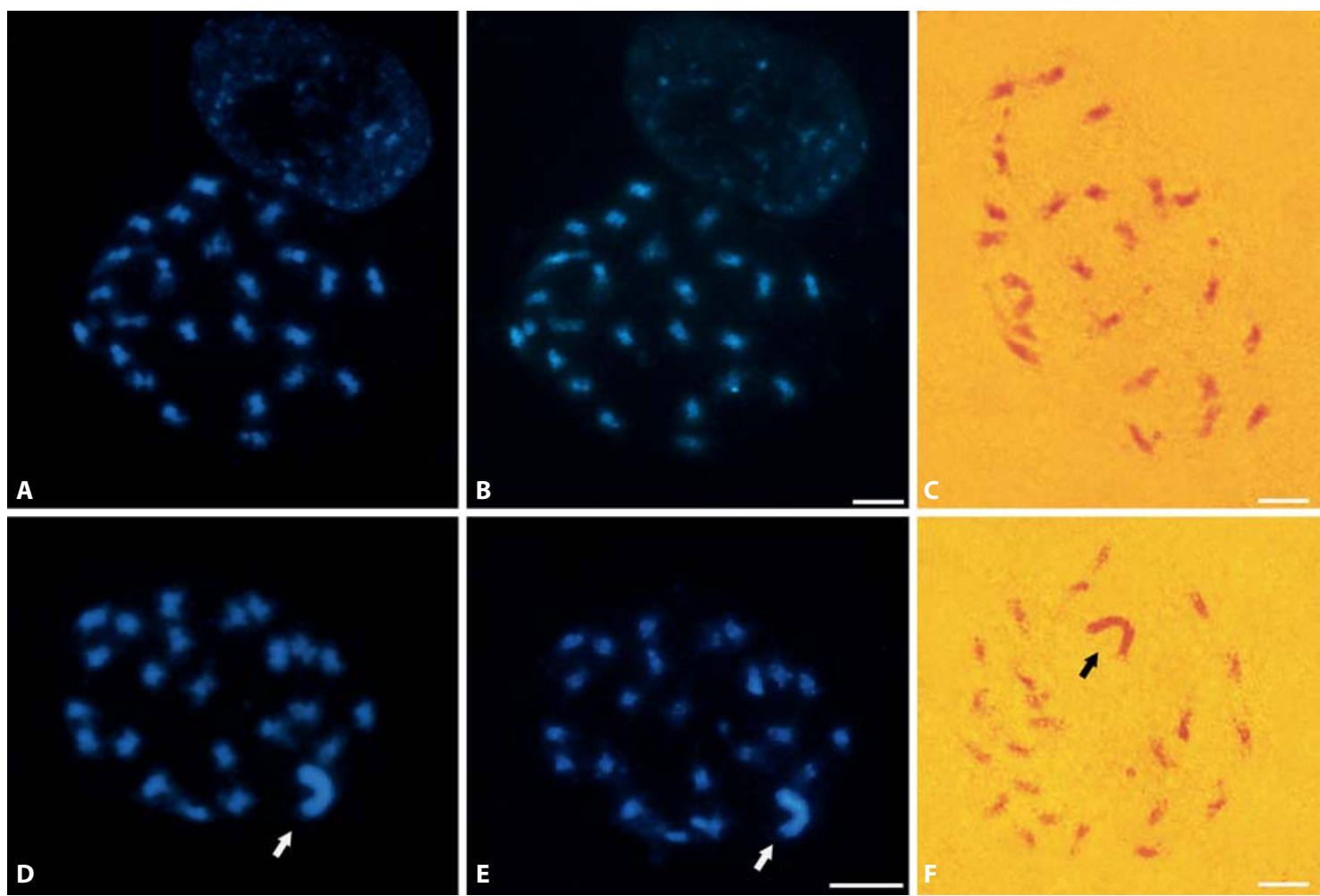

Fig. 4. C-banding in a C. grandis female (A-C) and male (D-F). A, D Metaphases stained with DAPI before C-banding. Chromosomes are stained along their entire length. B, E Metaphases showing centromeric and subterminal DAPI-positive regions, hence heterochromatic. The Y chromosome in $\mathbf{D}$ and $\mathbf{E}$ shows similar DAPI intensity before and after C-banding. C, F Pre-metaphases stained with Giemsa after C-banding. The heterochromatin is well-distributed on all chromosomes in $\mathbf{C}$ while it is concentrated on the $\mathrm{Y}$ chromosome in $\mathbf{F}$. Arrows in $\mathbf{D}-\mathbf{F}$ indicate the $\mathrm{Y}$ chromosome. Bar in $\mathbf{B}$ valid for $\mathbf{A}$, and in $\mathbf{E}$ valid for $\mathbf{D}$. Bars correspond to $5 \mu \mathrm{m}$.

Table 1. Morphology of C. grandis male and female chromosomes

\begin{tabular}{|c|c|c|c|c|c|c|}
\hline \multirow[t]{2}{*}{ Chromosome pairs } & \multicolumn{2}{|c|}{ Chromosome size, $\mu \mathrm{m}$} & \multicolumn{2}{|l|}{$\mathrm{AR}$} & \multicolumn{2}{|c|}{ Chromosome type } \\
\hline & male & female & male & female & male & female \\
\hline 1 & $2.28 \pm 0.25$ & $2.26 \pm 0.06$ & 1.13 & 1.21 & $\mathrm{~m}$ & $\mathrm{~m}$ \\
\hline 2 & $2.01 \pm 0.14$ & $2.03 \pm 0.13$ & 1.12 & 1.24 & $\mathrm{~m}$ & $\mathrm{~m}$ \\
\hline 3 & $1.87 \pm 0.14$ & $2.01 \pm 0.06$ & 1.17 & 1.22 & $\mathrm{~m}$ & $\mathrm{~m}$ \\
\hline 4 & $1.87 \pm 0.14$ & $1.96 \pm 0.05$ & 1.15 & 1.19 & $\mathrm{~m}$ & $\mathrm{~m}$ \\
\hline $5^{\mathrm{a}}$ & $1.75 \pm 0.21$ & $1.85 \pm 0.03$ & 1.19 & 1.16 & $\mathrm{~m}$ & $\mathrm{~m}$ \\
\hline 6 & $1.73 \pm 0.11$ & $1.78 \pm 0.02$ & 1.28 & 1.14 & $\mathrm{~m}$ & $\mathrm{~m}$ \\
\hline $7^{b}$ & $1.66 \pm 0.14$ & $1.75 \pm 0.04$ & 1.29 & 1.23 & $\mathrm{~m}$ & $\mathrm{~m}$ \\
\hline 8 & $1.66 \pm 0.14$ & $1.69 \pm 0.05$ & 1.23 & 1.14 & $\mathrm{~m}$ & $\mathrm{~m}$ \\
\hline 9 & $1.60 \pm 0.06$ & $1.65 \pm 0.04$ & 1.28 & 1.36 & $\mathrm{~m}$ & $\mathrm{~m}$ \\
\hline 10 & $1.56 \pm 0.03$ & $1.60 \pm 0.06$ & 1.22 & 1.32 & $\mathrm{~m}$ & $\mathrm{~m}$ \\
\hline 11 & $1.44 \pm 0.04$ & $1.58 \pm 0.08$ & 1.14 & 1.26 & $\mathrm{~m}$ & $\mathrm{~m}$ \\
\hline $12 X^{c}$ & $1.33 \pm 0.05$ & $1.35 \pm 0.12$ & 1.09 & 1.21 & $\mathrm{~m}$ & $\mathrm{~m}$ \\
\hline $12 \mathrm{Y}$ & $4.71 \pm 0.34$ & & 1.18 & & $\mathrm{~m}$ & \\
\hline
\end{tabular}

${ }^{a}$ Chromosome pairs with only $45 \mathrm{~S} .{ }^{\mathrm{b}}$ Chromosome pairs with $45 \mathrm{~S}$ and $5 \mathrm{~S}$ rDNA. ${ }^{\mathrm{c}}$ Likely X chromosome/X chromosome pair. $\mathrm{m}=$ Metacentric. The length of satellites is not included in the chromosome length. 
Table 2. Flow cytometric measurements for male and female C. grandis

\begin{tabular}{lllll}
\hline & Leaves & Samples & DNA content, pg/2C & SD \\
\hline Male & 2 & 12 & 0.943 & 0.005 \\
Female & 2 & 12 & 0.849 & 0.005 \\
\hline
\end{tabular}

Table 3. Chromosome numbers, lengths, $2 \mathrm{C}$-values, and inferred age of sex chromosomes in vascular plant species with heteromorphic sex chromosomes

\begin{tabular}{|c|c|c|c|c|c|c|c|}
\hline Species & $\begin{array}{l}\text { Chromosome } \\
\text { number, } 2 \mathrm{n}\end{array}$ & $\begin{array}{l}\text { Chromosomal sex } \\
\text { determination }\end{array}$ & $\begin{array}{l}\text { X chromosome length } \\
\mu \mathrm{m}\end{array}$ & $\begin{array}{l}\text { Y chromosome length } \\
\mu \mathrm{m}\end{array}$ & $\begin{array}{l}\text { DNA content }(2 \mathrm{C}) \\
\text { pg }\end{array}$ & $\begin{array}{l}\text { Age of species } \\
\text { or clade, myr }\end{array}$ & $\begin{array}{l}\text { References (studies } \\
\text { with age estimates) }\end{array}$ \\
\hline Podocarpus macrophyllus & 37,38 & $\mathrm{X}_{1} \mathrm{X}_{2} / \mathrm{Y}$ & unknown & 9.1 & unknown & unknown & Hizume et al. [1988] \\
\hline Coccinia grandis & 24 & $\mathrm{XX} / \mathrm{XY}$ & $\begin{array}{l}\text { indistinguishable from } \\
\text { autosomes }\end{array}$ & $\begin{array}{l}4.71 \text { ( } 10 \% \text { of male } \\
\text { genome weight) }\end{array}$ & $\begin{array}{l}M=0.943 \\
F=0.849\end{array}$ & $3-6$ & $\begin{array}{l}\text { Holstein and Renner } \\
\text { [2011]; Holstein [2012] }\end{array}$ \\
\hline Humulus japonicus & 16,17 & $\mathrm{XX} / \mathrm{XY}_{1} \mathrm{Y}_{2}$ & 3.11 & $\begin{array}{l}\mathrm{Y}_{1}=2.98 \\
\mathrm{Y}_{2}=2.75\end{array}$ & $\mathrm{M}=3.522$ & unknown & $\begin{array}{l}\text { Grabowska-Joachimiak } \\
\text { et al. [2006] }\end{array}$ \\
\hline Humulus lupulus & 20 & $\mathrm{XX} / \mathrm{XY}$ & $2.39^{\mathrm{a}}$ & 1.63 & $M=5.523$ & unknown & $\begin{array}{l}\text { Grabowska-Joachimiak } \\
\text { et al. [2006] }\end{array}$ \\
\hline Rumex acetosa & 14,15 & $\mathrm{XX} / \mathrm{XY}_{1} \mathrm{Y}_{2}$ & $\begin{array}{l}3 \% \text { of female genome } \\
\text { weight }\end{array}$ & $\begin{array}{l}Y_{1}=7.5 \\
Y_{2}=6.9 \\
\text { (20\% of male genome } \\
\text { weight) }\end{array}$ & $\begin{array}{l}M=7.498 \\
F=7\end{array}$ & $15-16$ & $\begin{array}{l}\text { Kurita and Kuroki } \\
\text { [1970]; Błocka-Wandas } \\
\text { et al. [2007] }\end{array}$ \\
\hline Silene latifolia & 24 & $\mathrm{XX} / \mathrm{XY}$ & $\begin{array}{l}\text { slightly smaller than } \\
\text { autosomes ( } 8 \% \text { of female } \\
\text { genome weight) }\end{array}$ & $\begin{array}{l}\text { much longer than } \\
\text { autosomes ( } 9 \% \text { of } \\
\text { male genome weight) }\end{array}$ & $\begin{array}{l}M=5.85 \\
F=5.73\end{array}$ & $3.5-24$ & $\begin{array}{l}\text { Siroky et al. [2001] } \\
\text { (Moore et al. [2003]; } \\
\text { Nicolas et al. [2005]; } \\
\text { Rautenberg et al. [2012]) }\end{array}$ \\
\hline
\end{tabular}

a Putative X chromosome.

ship between the ages of sex chromosomes and the extent of $\mathrm{Y} /$ autosome or $\mathrm{X} / \mathrm{Y}$ divergence. In terms of total genome size, $C$. grandis has the smallest genomes of all vascular plants with heteromorphic sex chromosomes (table 3).

\section{Discussion}

The Extent of Y/Autosome Divergence in C. grandis

Our results show that $C$. grandis has the greatest $\mathrm{Y} / \mathrm{au}$ tosome size difference documented in vascular plants $(2.43 \mu \mathrm{m}$; table 1): The Y chromosome of C. grandis is 2.06 times larger than the largest chromosome (in contrast to previous reports of it being $2.5 \times$ or $3-4 \times$ longer than the largest autosome; Bhaduri and Bose [1947]; Guha et al. [2004]). Experimental work on C. grandis, using diploid individuals and artificial polyploids, has established the male-determining effect of the presence of the Y chromosome; individual tetraploid plants with a karyotype of XXXY still were normal males [Roy and Roy, 1971]. As previously reported, the chromosome number of C. grandis is $2 \mathrm{n}=22+\mathrm{XX}$ or $22+\mathrm{XY}$ [Kumar and Deodikar, 1940 probably by mistake reported $2 \mathrm{n}=26$ for both sexes; Bhaduri and Bose, 1947; Chakravorti, 1948; Kumar and Vishveshwaraiah, 1952].

The degree of divergence of the male and female genome in C. grandis is evident also from the $\mathrm{C}$-values: The difference between the male and female genomes is almost $0.1 \mathrm{pg}$ of DNA, which is in the range of an entire small plant genome (Genlisea margaretae, $1 \mathrm{C}=0.065 \mathrm{pg}$; Greilhuber et al. [2006]) and amounts to ca. $10 \%$ of the $C$. grandis genome $(0.094 \mathrm{pg} / 2 \mathrm{C})$. In Silene latifolia, the male genome weighs $5.85 \mathrm{pg} / 2 \mathrm{C}$, the female $5.73 \mathrm{pg} / 2 \mathrm{C}$, with the $\mathrm{Y}$ chromosome making up ca. $9 \%$ of the male genome and the $\mathrm{X}$ chromosome ca. $8 \%$ of the female genome [Siroky et al., 2001].

Autosome sizes in C. grandis vary from 2.28 to 1.44 $\mu \mathrm{m}$ in males and from 2.26 to $1.58 \mu \mathrm{m}$ in females (table 1), both sexes having exclusively metacentric chromosomes (fig. 2), with the $\mathrm{X}$ chromosome probably the smallest chromosome of the complement, an assumption that needs testing. Both sexes also have the same number 
and distribution of rDNA sites on the autosomes (fig. 1C, F) while no rDNA site was detected on the Y chromosome. At least one of the chromosome pairs of C. grandis labeled with $45 \mathrm{~S}$ rDNA bears a secondary constriction, but in contrast to previous reports [Bhaduri and Bose, 1947; Agarwal and Roy, 1984; Chattopadhyay and Sharma, 1991] no secondary constriction was seen on the $Y$ chromosome. In species of Silene, Rumex and Humulus with heteromorphic sex chromosomes, the rDNA sites are also restricted to autosomes [Siroky et al., 2001; Karlov et al., 2003; Cuñado et al., 2007; Grabowska-Joachimiak et al., 2011], but Spinacia oleracea has a 45S rDNA site on the X chromosome [Lan et al., 2006]. It thus appears that rDNA does not greatly or regularly contribute to the morphological divergence of plant Y chromosomes.

Of the heteromorphic sex chromosomes that have been studied, most have undergone extensive rearrangements or end-to-end fusions. Thus, in Podocarpus macrophyllus $\left(2 \mathrm{n}=34+\mathrm{X}_{1} \mathrm{X}_{2} \mathrm{Y}\right.$; table 3$)$, females have 38 telocentric chromosomes while males have 36 telocentric and 1 large submetacentric Y chromosome. In meiosis I, the P. macrophyllus $\mathrm{Y}$ chromosome pairs with 2 telocentric chromosomes to form a trivalent, suggesting it may have originated from a telocentric fusion of 2 telocentric chromosomes [Hizume et al., 1988]. In Humulus japonicus, a species with an $\mathrm{XY}_{1} \mathrm{Y}_{2}$ sex chromosome system (table 3 ), interstitial telomeric sites on 1 autosome pair also point to a fusion event having led to the reduction of the chromosome number from 18 to $14+\mathrm{XY}_{1} \mathrm{Y}_{2}$ [GrabowskaJoachimiak et al., 2011]. And in S. latifolia telomere-homologous sequences on the sex chromosomes provide evidence of a translocation of subtelomeric sites [Uchida et al., 2002]. In C. grandis, however, we did not find any telomeric sequences at interstitial sites (fig. 1B, E), suggesting that such fusions have not contributed, at least not recently, to the elongation of this species' $Y$ chromosome.

Our GISH experiments revealed the preferential distribution of repetitive sequences in male and female individuals of C. grandis. In plants with small genomes, GISH signals tend to be unclear and restricted to pericentromeric heterochromatin blocks [Ali et al., 2004]. In C. grandis males, however, male and female genomic probes clearly differed in spite of the small genome size of the species (female individuals $0.849 \mathrm{pg} / 2 \mathrm{C}$; male individuals $0.943 \mathrm{pg} / 2 \mathrm{C}$ ). Male genomic DNA (fig. $1 \mathrm{H}$ ) hybridized to centromeric and some subterminal regions of the chromosomes, while female genomic DNA (fig. 1I) hybridized mainly to centromeric regions. Both genomic probes hybridized to the $\mathrm{Y}$ chromosome, and C-banding results indicate that the $\mathrm{Y}$ chromosome is indeed mostly heterochromatic (fig. 4D, F). This fits with repetitive sequences forming large clusters in the centromeric and subterminal regions of the autosomes and having accumulated on the Y.

The types of repetitive DNA in the centromere of the C. grandis Y appear to be different from those in the centromeres of the autosomes and X chromosome (fig. 1I, inset). The situation might resemble that found in S. latifolia, where the centromeres of the autosomes and X chromosome are rich in Silene tandem repeat centromeric sequences and transposable elements, while the $\mathrm{Y}$ centromere contains Silene tandem repeat Y sequences [Cermak et al., 2008; Kejnovsky et al., 2009]. In C. grandis Y chromosomes, male-specific regions became progressively more visible with increasing concentrations of female blocking DNA (fig. 1J-L), and terminal regions that failed to label with either male or female DNA probably are pseudoautosomal regions, still engaged in recombination. In meiosis, there is an end-to-end connection between the $\mathrm{X}$ and the $\mathrm{Y}$ chromosome, but the $\mathrm{X}$ does not otherwise differ from the remaining chromosomes.

\section{Ages of Plant Y Chromosomes and Their Size Change over Time}

An increase in the size of some, but not all (table 3), vascular plant $Y$ chromosomes has been attributed to the accumulation of repetitive DNA, especially transposable elements (Bergero et al. [2008], Cermak et al. [2008], Kejnovsky et al. [2009]: Silene latifolia; Mariotti et al. [2006, 2009], Cuñado et al. [2007]: Rumex acetosa). Such accumulation is thought to occur because of inefficient selection in non-recombining regions [Charlesworth and Charlesworth, 2000]. The best studied plant Y chromosome, that of S. latifolia, indeed does show signs of degeneration, including reduced levels of polymorphism, reduced gene expression levels, and transposable element insertion in Y genes [Filatov et al., 2000; Marais et al., 2008]. The degeneration, however, is less pronounced than that documented from animal sex chromosomes, perhaps because they are older or because of purifying selection during the haploid stage of the embryophyte life cycle [Armstrong and Filatov, 2008; Bergero and Charlesworth, 2011; Chibalina and Filatov, 2011]. An estimated $62 \%$ of the genes of $A$. thaliana are expressed in its haploid pollen tubes [Honys and Twell, 2003]. In liverworts, in which the haploid gametophyte is the predominant stage and in which there is no XX recombination, sex chromosome dimorphism may follow a different trajectory from that in vascular plants, where the diploid spo- 
rophyte is the predominant life phase (Yamato et al. [2007]; Bachtrog et al. [2011]; but see Jamilena et al. [2008] for the opposite view that the Marchantia polymorpha $\mathrm{Y}$ is in an advanced stage of degeneration, caused by the accumulation of a large amount of unique repetitive DNA sequences).

Comparing the speed of X/Y divergence is complicated by our poor understanding of the absolute ages of plant sex chromosomes. Thus, the sex chromosomes in the $S$. latifolia species group are approximately between 3.5 and 24 myr old. Synonymous site divergence values suggest ages of 8-24 myr [Moore et al., 2003] or 5-10 myr [Nicolas et al., 2005], while a phylogenetic study that used a relaxed molecular-clock approach instead inferred an age of the Silene clade with sex chromosomes of ca. $3.5 \mathrm{myr}$ (Rautenberg et al. [2012] fig. 4: the node in question is the divergence of S. latifolia from S. samia). Molecular-clock work in liverworts is scarce, but judging from genetic branch lengths Frullania species are $>2$ myr old (Pleistocene; Bombosch et al. [2010]).

It has been hypothesized that the evolution of plant sex chromosomes may proceed from the initial recombination suppression and the expansion of the male-specific region through increasing heteromorphy between the $\mathrm{X}$ and $Y$ chromosomes, followed by severe degeneration of the $Y$ to its eventual loss (Ming et al. [2011] fig. 2). So far, there is no evidence for such a trajectory (table 3), and the limited data rather suggest that transposon accumulation and chromosome rearrangements occur idiosyncratically. It is clear, however, that plant sex chromosomes are all relatively young.

The sequencing and assembly of plant $\mathrm{Y}$ chromosomes is technically not yet feasible, and it is therefore unclear which transposon families they may accumulate. Nor is it clear in general how fast plant repetitive DNA is turned over [Renny-Byfield et al., 2011; Piednoel et al., 2012]. The only assembled Y chromosomes so far are those of Homo sapiens and chimpanzee [Skaletsky et al., 2003; Hughes et al., 2010]. However, once next-generation sequencing techniques yield longer read lengths, the relatively small genome of C. grandis compared to S. latifolia (c. 0.94 pg/2C vs. 5.85 pg; Costich et al. [1991]) and its phylogenetic proximity to the fully assembled crop species C. sativus [Huang et al., 2009] may make it a potentially useful additional system for the study of plant sex chromosomes.

\section{Acknowledgments}

We thank Abbagani Sadanandam, Kakatiya University, Bangalore, for seeds of C. grandis; Hanna Schneeweiss, University of Vienna, for plasmids; Martina V. Silber for numerous discussions, and 2 anonymous reviewers for their helpful suggestions. Funding came from the German Science Foundation (DFG RE-603/61 and 6-2).

\section{References}

Agarwal PK, Roy RP: Karyotype of Coccinia indica. Indian J Genet Plant Breed 44:117-120 (1984).

-Ali HB, Lysak MA, Schubert I: Genomic in situ hybridization in plants with small genomes is feasible and elucidates the chromosomal parentage in interspecific Arabidopsis hybrids. Genome 47:954-960 (2004).

Armstrong SJ, Filatov DA: A cytogenetic view of sex chromosome evolution in plants. Cyt Genome Res 120:241-246 (2008).

-Bachtrog D, Kirkpatrick M, Mank JE, McDaniel SF, Pires JC, et al: Are all sex chromosomes created equal? Trends Genet 27:350-357 (2011).

Bergero R, Charlesworth D: Preservation of the $\mathrm{Y}$ transcriptome in a 10 -million-year-old plant sex chromosome system. Curr Biol 21: 1470-1474 (2011).

- Bergero R, Forrest A, Charlesworth D: Active miniature transposons from a plant genome and its non-recombining $\mathrm{Y}$ chromosome. Genetics 178:1085-1092 (2008).
Bhaduri P, Bose P: Cyto-genetical investigations in some common cucurbits, with special reference to fragmentation of chromosomes as a physical basis of speciation. J Genet 48:237256 (1947).

Błocka-Wandas M, Sliwinska E, GrabowskaJoachimiak A, Musial K, Joachimiak AJ: Male gametophyte development and two different DNA classes of pollen grains in Rumex acetosa $\mathrm{L}$., a plant with an $\mathrm{XX} / \mathrm{XY}_{1} \mathrm{Y}_{2}$ sex chromosome system and a female-biased sex ratio. Sex Plant Reprod 20:171-180 (2007).

- Bombosch A, Wieneke A, Busch A, Jonas R, Hentschel J, et al: Narrow species concepts in the Frullania dilatata-appalachiana-eboracensis complex (Porellales, Jungermanniopsida): evidence from nuclear and chloroplast DNA markers. Plant Syst Evol 290:151-158 (2010).
Borchert T, Fuchs J, Winkelmann T, Hohe A: Variable DNA content of Cyclamen persicum regenerated via somatic embryogenesis: rethinking the concept of long-term callus and suspension cultures. Plant Cell Tiss Organ Cult 90:255-263 (2007).

Cermak T, Kubat Z, Hobza R, Koblizkova A, Widmer A, et al: Survey of repetitive sequences in Silene latifolia with respect to their distribution on sex chromosomes. Chromosome Res 16:961-976 (2008).

Chakravorti AK: Cytology of Coccinia indica W. \& A. with reference to the behavior of its sexchromosomes. Proc Ind Acad Sci B 27:74-86 (1948).

Charlesworth B, Charlesworth D: The degeneration of Y chromosomes. Philos Trans R Soc Lond B Biol Sci 355:1563-1572 (2000).

Chattopadhyay D, Sharma AK: Chromosome studies and nuclear DNA in relation to sex difference and plant habit in two species of Cucurbitaceae. Cytologia 56:409-417 (1991). 
- Chibalina MV, Filatov DA: Plant Y chromosome degeneration is retarded by haploid purifying selection. Curr Biol 21:1475-1479 (2011).

- Costich DE, Meagher TR, Yurkow EJ: A rapid means of sex identification in Silene latifolia by use of flow cytometry. Plant Mol Biology Reporter 9:359-370 (1991).

-Cuñado N, Navajas-Pérez R, de la Herrán R, Ruiz Rejón C, Ruiz Rejón M, et al: The evolution of sex chromosomes in the genus Rumex (Polygonaceae): identification of a new species with heteromorphic sex chromosomes. Chromosome Res 15:825-832 (2007).

- Divashuk MG, Alexandrov OS, Kroupin PY, Karlov GI: Molecular cytogenetic mapping of Humulus lupulus sex chromosomes. Cytogenet Genome Res 134:213-219 (2011).

-Filatov DA, Moneger F, Negrutiu I, Charlesworth D: Low variability in a Y-linked plant gene and its implications for $\mathrm{Y}$ chromosome evolution. Nature 404:388-390 (2000).

- Galbraith DW, Harkins KR, Maddox JM, Ayres NM, Sharma DP, Firoozabady E: Rapid flow cytometric analysis of the cell cycle in intact plant tissues. Science 220:1049-1051 (1983).

-Grabowska-Joachimiak A, Sliwinska E, Pigula M, Skomra U, Joachimiak AJ: Genome size in Humulus lupulus L. and H. japonicus Siebold \& Zucc. (Cannabaceae). Acta Soc Bot Pol 75:207-214 (2006).

-Grabowska-Joachimiak A, Mosiolek M, Lech A, Góralski G: C-banding/DAPI and in situ hybridization reflect karyotype structure and sex chromosome differentiation in Humulus japonicus Siebold \& Zucc. Cytogenet Genome Res 132:203-211 (2011).

-Greilhuber J, Borsch T, Müller K, Worberg A, Porembski S, Barthlott W: Smallest angiosperm genomes found in Lentibulariaceae, with chromosomes of bacterial size. Plant Biol 8:770-777 (2006).

Guerra M: Reviewing the chromosome nomenclature of Levan et al. Rev Brasil Genet 4:741743 (1986).

Guha A, Sinha RK, Sinha S: Average packing ratio as a parameter for analyzing the karyotypes of dioecious cucurbits. Caryologia 57: 117-120 (2004).

-Hizume M, Shiraishi H, Tanaka A: A cytological study of Podocarpus macrophyllus with special reference to sex chromosomes. Jap J Genet 63:413-423 (1988).

-Hobza R, Lengerova M, Svoboda J, Kubekova H, Kejnovsky E, Vyskot B: An accumulation of tandem DNA repeats on the $\mathrm{Y}$ chromosome in Silene latifolia during early stages of sex chromosome evolution. Chromosoma 115: 376-382 (2006).

Holstein N: Evolution, Biogeography, and Monographic Treatment of Coccinia (Cucurbitaceae) (Doctoral dissertation, Faculty of Biology, Ludwig-Maximilians University (LMU), Munich, 2012).

Holstein N, Renner SS: A dated phylogeny and collection records reveal repeated biome shifts in the African genus Coccinia (Cucurbitaceae). BMC Evol Biol 11:28 (2011).
Honys D, Twell D: Comparative analysis of the Arabidopsis pollen transcriptome. Plant Physiol 132:640-652 (2003).

Huang S, Li R, Zhang Z, Li L, Gu X, et al: The genome of the cucumber, Cucumis sativus $\mathrm{L}$. Nat Genet 41:1275-1281 (2009).

-Hughes JF, Skaletsky H, Pyntikova T, Graves TA, Daalen SK, et al: Chimpanzee and human Y chromosomes are remarkably divergent in structure and gene content. Nature 463:536539 (2010).

Ijdo JW, Wells RA, Baldini A, Reeders ST: Improved telomere detection using a telomere repeat probe (TTAGGG)n generated by PCR. Nucl Acids Res 19:17 (1991).

-Jamilena M, Mariotti B, Manzano S: Plant sex chromosomes: molecular structure and function. Cytogenet Genome Res 120:255264 (2008).

Karlov GI, Danilova TV, Horlemann C, Weber G: Molecular cytogenetics in hop (Humulus lupulus L.) and identification of sex chromosomes by DAPI-banding. Euphytica 132: 185-190 (2003).

- Kejnovsky E, Hobza R, Cermak T, Kubat Z, Vyskot B: The role of repetitive DNA in structure and evolution of sex chromosomes in plants. Heredity 102:533-541 (2009).

Kumar LS, Deodikar GB: Sex chromosomes of Coccinia indica Wight and Arn. Curr Sci 9: 128-130 (1940).

Kumar LS, Vishveshwaraiah S: Sex mechanism in Coccinia indica Wight and Arn. Nature 170:330-331 (1952).

Kurita M, Kuroki Y: Y-chromosome and heterochromatin in Rumex acetosa. Jap J Genet 45: 255-260 (1970).

Lan T, Zhang S, Liu B, Li X, Chen R, Song W: Differentiating sex chromosomes of the dioecious Spinacia oleracea L. (spinach) by FISH of 45S rDNA. Cytogenet Genome Res 114: 175-177 (2006).

- Lengerova M, Kejnovsky E, Hobza R, Macas J, Grant SR, Vyskot B: Multicolor FISH mapping of the dioecious model plant, Silene latifolia. Theor Appl Genet 108:1193-1199 (2004).

- Liu Z, Moore PH, Ma H, Ackerman CM, Ragiba $\mathrm{M}$, et al: A primitive $\mathrm{Y}$ chromosome in $\mathrm{Pa}$ paya marks the beginning of sex chromosome evolution. Nature 427:348-352 (2004).

-Marais GA, Nicolas M, Bergero R, Chambrier P, Kejnovsky E, et al: Evidence for degeneration of the $\mathrm{Y}$ chromosome in the dioecious plant Silene latifolia. Curr Biol 18:545-549 (2008).

Mariotti B, Navajas-Pérez R, Lozano R, Parker JS, de la Herrán R, et al: Cloning and characterization of dispersed repetitive DNA derived from microdissected sex chromosomes of Rumex acetosa. Genome 49:114-121 (2006).

Mariotti B, Manzano S, Kejnovsky E, Vyskot B, Jamilena M: Accumulation of Y-specific satellite DNAs during the evolution of Rumex acetosa sex chromosomes. Mol Gen Genomics 281:249-259 (2009).
Ming R, Bendahmane A, Renner SS: Sex chromosomes in land plants. Annu Rev Plant Biol 62:485-514 (2011)

-Moore RC, Kozyreva O, Lebel-Hardenack S, Siroky J, Hobza R, et al: Genetic and functional analysis of DD44, a sex-linked gene from the dioecious plant Silene latifolia, provides clues to early events in sex chromosome evolution. Genetics 163:321-334 (2003).

- Navajas-Pérez R, de la Herrán R, López González G, Jamilena M, Lozano R, et al: The evolution of reproductive systems and sex-determining mechanisms within Rumex (Polygonaceae) inferred from nuclear and chloroplastidial sequence data. Mol Biol Evol 22:19291939 (2005).

- Nicolas M, Marais G, Hykelova V, Janousek B Laporte V, et al: A gradual process of recombination restriction in the evolutionary history of the sex chromosomes in dioecious plants. PLoS Biol 3:e4 (2005).

Piednoel M, Aberer AJ, Schneeweiss GM, Macas J, Novak P, et al: Next generation sequencing reveals the impact of LTR retrotransposons on genome dynamics in a clade of increasingly parasitic angiosperms. Mol Biol Evol 2012;29:3601-3611.

Rautenberg A, Sloan DB, Alden V, Oxelman B: Phylogenetic relationships of Silene multinervia and Silene section Conoimorpha (Caryophyllaceae). Syst Bot 37:226-237 (2012).

-Renny-Byfield S, Chester M, Kovařík A, Le Comber SC, Grandbastien MA, et al: Next generation sequencing reveals genome downsizing in allotetraploid Nicotiana tabacum, predominantly through the elimination of paternally derived repetitive DNAs. Mol Biol Evol 28:2843-2854 (2011).

Roy RP, Roy PM: Mechanism of sex determination in Coccinia indica. J Indian Bot Soc 50A:391-400 (1971).

Ruiz Rejón C, Jamilena M, Garrido Ramos M, Parker JS, Ruiz Rejón M: Cytogenetic and molecular analysis of the multiple sex chromosome system of Rumex acetosa. Heredity 72:209-215 (1994).

- Sakamoto K, Ohmido N, Fukui K, Kamada H, Satoh S: Site-specific accumulation of a LINE-like retrotransposon in a sex chromosome of the dioecious plant Cannabis sativa. Plant Mol Biol 44:723-732 (2000).

Schaefer H, Renner SS: Phylogenetic relationships in the order Cucurbitales and a new classification of the gourd family (Cucurbitaceae). Taxon 60:122-138 (2011).

Schmidt T, Schwarzacher T, Heslop-Harrison JS: Physical mapping of rRNA genes by fluorescent in situ hybridization and structural analysis of 5S rRNA genes and intergenic spacer sequences in sugar beet (Beta vulgaris). Theor Appl Genet 88:629-636 (1994).

Schwarzacher T, Heslop-Harrison P: Practical in situ hybridization (BIOS Scientific publishers, Oxford 2000). 
Schwarzacher T, Ambros P, Schweizer D: Application of Giemsa banding to orchid karyotype analysis. Plant Syst Evol 134:293-297 (1980).

-Shibata F, Hizume M, Kuroki Y: Chromosome painting of $Y$ chromosomes and isolation of a Y chromosome-specific repetitive sequence in the dioecious plant Rumex acetosa. Chromosoma 108:266-270 (1999).

Shibata F, Hizume M, Kuroki Y: Differentiation and the polymorphic nature of the $\mathrm{Y}$ chromosomes revealed by repetitive sequences in the dioecious plant, Rumex acetosa. Chromosome Res 8:229-236 (2000).
-Siroky J, Lysak MA, Doležel J, Kejnovsky E, Vyskot B: Heterogeneity of rDNA distribution and genome size in Silene spp. Chromosome Res 9:387-393 (2001).

Skaletsky H, Kuroda-Kawaguchi T, Minx PJ, Cordum HS, Hillier L, et al: The male-specific region of the human $Y$ chromosome is a mosaic of discrete sequence classes. Nature 423:825-837 (2003).

Spigler RB, Lewers KS, Main DS, Ashman T-L: Genetic mapping of sex determination in a wild strawberry, Fragaria virginiana, reveals earliest form of sex chromosome. Heredity 101:507-517 (2008).

Spigler RB, Lewers KS, Johnson AL, Ashman T-L: Comparative mapping reveals autosomal origin of sex chromosome in octoploid Fragariavirginiana.JHered 101(suppl.):S107S117 (2010).
Uchida W, Matsunaga S, Sugiyama R, Shibata F, Kazama Y, et al: Distribution of interstitial telomere-like repeats and their adjacent sequences in a dioecious plant, Silene latifolia. Chromosoma 111:313-320 (2002).

Yamato KT, Ishizaki K, Fujisawa M, Okada S, Nakayama S, et al: Gene organization of the liverwort $\mathrm{Y}$ chromosome reveals distinct sex chromosome evolution in a haploid system. Proc Natl Acad Sci USA 104:6472-6477 (2007).

Yu Q, Navajas-Pérez R, Tong E, Robertson J, Moore $\mathrm{PH}$, et al: Recent origin of dioecious and gynodioecious $\mathrm{Y}$ chromosomes in papaya. Trop Plant Biol 1:49-57 (2008). 